\title{
Mapping of fire blight resistance in Malus xrobusta 5 flowers following artificial inoculation
}

\author{
Andreas Peil ${ }^{1 *}$ (D), Christine Hübert ${ }^{2}$, Annette Wensing ${ }^{2}$, Mary Horner ${ }^{3}$, Ofere Francis Emeriewen ${ }^{1}$, Klaus Richter ${ }^{4}$, \\ Thomas Wöhner ${ }^{1}$, David Chagné ${ }^{5}$, Carolina Orellana-Torrejon ${ }^{5}$, Munazza Saeed $^{5}$, Michela Troggio ${ }^{6}$, Erika Stefani ${ }^{6}$, \\ Susan E. Gardiner ${ }^{5}$, Magda-Viola Hanke', Henryk Flachowsky ${ }^{1}$ and Vincent G.M. Bus ${ }^{3}$
}

\begin{abstract}
Background: Although the most common path of infection for fire blight, a severe bacterial disease on apple, is via host plant flowers, quantitative trait loci (QTLs) for fire blight resistance to date have exclusively been mapped following shoot inoculation. It is not known whether the same mechanism underlies flower and shoot resistance.

Results: We report the detection of a fire blight resistance QTL following independent artificial inoculation of flowers and shoots on two F1 segregating populations derived from crossing resistant Malus xrobusta 5 (Mr5) with susceptible 'Idared' and 'Royal Gala' in experimental orchards in Germany and New Zealand, respectively. QTL mapping of phenotypic datasets from artificial flower inoculation of the 'Idared' $\times$ Mr5 population with Erwinia amylovora over several years, and of the 'Royal Gala' $\times$ Mr5 population in a single year, revealed a single major QTL controlling floral fire blight resistance on linkage group 3 (LG3) of Mr5. This QTL corresponds to the QTL on LG3 reported previously for the 'Idared' $\times$ Mr5 and an ' $M 9$ ' $\times$ Mr5 population following shoot inoculation in the glasshouse. Interval mapping of phenotypic data from shoot inoculations of subsets from both flower resistance populations re-confirmed that the resistance QTL is in the same position on LG3 of Mr5 as that for flower inoculation. These results provide strong evidence that fire blight resistance in Mr5 is controlled by a major QTL on LG3, independently of the mode of infection, rootstock and environment.
\end{abstract}

Conclusions: This study demonstrates for the first time that resistance to fire blight caused by Erwinia amylovora is independent of the mode of inoculation at least in Malus xrobusta 5.

Keywords: Malus xrobusta 5, Erwinia amylovora, Fire blight resistance, QTL mapping, Orchard inoculation

\section{Background}

The domesticated apple (Malus domestica Borkh.), a pome fruit species, is one of the most important fruit crops grown in temperate climate zones [1]. The most damaging bacterial disease affecting apple is fire blight, caused by Erwinia amylovora (Burrill) Winslow et al. [2]. Fire blight can infect its host plants via flowers (blossom blight), twigs (shoot blight) and suckers. Blossom blight leads to a reduction in crop yield, and shoot blight destroys the annual wood that bears the fruit spurs for

\footnotetext{
* Correspondence: andreas.peil@julius-kuehn.de

${ }^{1}$ Julius Kühn-Institut (JKI), Federal Research Centre for Cultivated Plants, Institute for Breeding Research on Fruit Crops, Pillnitzer Platz 3a, 01326 Dresden, Germany

Full list of author information is available at the end of the article
}

the following season, while subsequent progression of the bacteria into large limbs or the trunk can kill the tree [3]. As most commercial rootstocks are highly sensitive to the disease, an infection of the rootstock via suckers or other pathways usually ends with death of both rootstock and scion [4]. Infestation of orchards with fire blight can cause enormous economic losses because of the necessity for elaborative sanitation measures, decreased yield, and even the eradication of trees. Van der Zwet et al. [5] reviewed economic losses in pome fruit growing over several decades. One of the last major events they listed was the fire blight outbreak in 2007 in Switzerland, associated with economic losses of around US\$27.5 million. Some antibiotics, such a

(C) The Author(s). 2019 Open Access This article is distributed under the terms of the Creative Commons Attribution 4.0 International License (http://creativecommons.org/licenses/by/4.0/), which permits unrestricted use, distribution, and 
streptomycin, kasugamycin or oxytetracyclin, have been shown to treat fire blight effectively; however, they are registered for use in plant protection in only a few countries [6]. Their use can also reduce export opportunities when importing countries implement non-tariff trade barriers. Gianessi et al. [7] reported that US apple growers spend about US $\$ 2.8$ million yearly on antibiotic sprays to prevent E. amylovora infection. Alternative products based on antagonists, resistance inducers or disinfecting chemicals are frequently less effective, or have a greater variation in effectiveness [8].

Another approach to control fire blight is the planting of apple cultivars that are resistant to the disease. Currently, the worldwide production of apples is dominated by a few cultivars [9], which are all more or less susceptible to fire blight. The breeding of cultivars that are both competitive in the market and resistant to fire blight is a challenge, since strong resistances are mainly found in wild Malus species [3, 10, 11], and their use in breeding requires several generations of pseudo-backcrosses. An understanding of the genetics of fire blight resistance is a prerequisite for target-oriented resistance breeding; to date several quantitative trait loci (QTLs) conferring various degrees of resistance to fire blight in Malus have been reported. The first fire blight resistance QTL, explaining up to $40 \%$ of the phenotypic variance, was mapped to linkage group (LG) 7 of 'Fiesta' $[12,13]$. Since then, other major QTLs have been detected on LG3 of Mr5 [14, 15], on LG12 of the ornamental crab apple cultivar 'Evereste' and species M. floribunda [16] and M. xarnoldiana [17]. A very strong QTL maps to LG10 of $M$. fusca explaining up to $66 \%$ of the phenotypic variance [18]. A candidate gene underlying the fire blight resistance QTL of Mr5 (FB_MR5) was identified [19] and Broggini et al. [20] confirmed the function of the FB_MR5 CC-NBS-LRR resistance gene in transgenic 'Gala'. Recently, Emeriewen et al. [21] reported the identification of a candidate resistance gene in $M$. fusca, which possesses a different resistance mechanism.

Furthermore, susceptibility of a given apple variety also depends on the strain of E. amylovora [22-24], as some have been identified that can overcome the fire blight resistance of a wild species, such as Mr5 [25, 26]. Vogt et al. [27] proposed a gene-for-gene interaction in the host-pathogen system Mr5 - E. amylovora, whereby a single nucleotide polymorphism (SNP) in the avrRPT2 $2_{E A}$ effector leading to a change from cysteine to serine determines the difference between a compatible and an incompatible interaction. This same change in isolate Ea3049, overcoming the major QTL on LG3, enabled the detection of minor QTLs on other linkage groups [26, 28]. Recently, another gene-for-gene relationship was proposed by Wöhner et al. [29], who reported that an E. amylovora Eop1 deletion mutant was able to cause considerable necrosis on 'Evereste' and M. floribunda 821.
Although trees are infected by E. amylovora primarily through the flowers under natural conditions in the field [30, 31], resistance phenotyping in the genetic mapping studies listed above were performed by artificial inoculation of grafted scions in the glasshouse, using either the cut-leaf $[32,33]$ or the hypodermic needle technique [34]. In studies comparing the resistance of shoots and flowers, Thibault and Le Lezec [35] reported a weak correlation between them, while Maroofi and Mostafavi [36] found a positive association. Nevertheless, large discrepancies between flower and shoot resistance have been found in a few cultivars. For example, 'Reinette Clochard' shoots were highly susceptible, but flowers had low susceptibility, while the opposite was found for 'Blushing Golden', 'Mutsu' and 'Royal Gala' [37].

Flowering time and climatic conditions at blooming [38, 39], length of blooming and flower age [40, 41], flower morphology [42], nectar production and composition [43, 44] and volatile organic compounds emission [31] may influence flower blight incidence. To date, it is unclear whether resistances to fire blight of shoots and flowers are governed by the same mechanism, or if the observed differences are based mainly on differing environmental conditions. Here, we report the mapping of fire blight resistance in Mr5 following separate artificial inoculations of flowers and shoots in the field and the glasshouse, respectively, in two countries. The F1 generation from a cross of 'Royal Gala' $\times$ Mr5 was planted in New Zealand using a single rootstock, while the progeny from a cross of 'Idared' $\times \mathrm{Mr} 5$ was planted in Germany on two different rootstocks. Part of the same 'Idared' $\times$ Mr5 population had previously been used for genetic mapping of resistance to fire blight by evaluation of shoot infections under glasshouse conditions [14, 26, 28, 45].

\section{Results}

\section{Flower phenotyping}

The harmonized classification for flower infection by fire blight (Table 1; Fig. 1a, b) facilitated the assessment of symptoms in both Germany and New Zealand.

In Germany, a total of 58 flower clusters on Mr5 were inoculated between 2011 and 2013, but not a single cluster exhibited symptoms, whereas the inoculation of 297 floral clusters in the 2015-2017 period resulted in low infection rates, ranging from 0.08 to 0.28 (Table 2). The scores for 'Idared' in the same 2015-2017 period ranged from 2.01 to 3.71 (Table 2).

In total, 12,515 flower clusters were inoculated on the seedling progeny over the 6 years of the experiment, with 228 (95.4\%) out of the initial 239 'Idared' $\times$ Mr5 progeny on 'M9' rootstock, and 148 (98.7\%) progeny out of 150 on 'B9' rootstock inoculated at least once in the periods 2011-2013 and 2015-2017, respectively (Table 2). The number of inoculated flower clusters per genotype is shown in Additional file 4: Table S1. The highest rate of infection was recorded in 2011 when the mean disease 
Table 1 Ranking systems used in New Zealand and Germany for phenotypic assessment of apple floral clusters after inoculation with Erwinia amylovora

\begin{tabular}{lllll}
\hline New Zealand & & & Germany \\
\hline Symptom description & Class & Harmonized & Class & Symptom description \\
healthy & 0 & 0 & 0 & healthy \\
& & & 1 & possible floral infection \\
floral infection & 1 & 1 & 2 & clear floral infection \\
flowers and peduncle infected & 2 & 2 & 3 & flowers and peduncle infected \\
flowers and bourse infected & 3 & 3 & 4 & flowers and bourse leaves infected \\
& & & 5 & flowers and bourse infected \\
floral cluster, bourse and bourse shoot infected & 4 & 4 & 6 & floral cluster, bourse and possibly shoot infected \\
necrosis spread $<5 \mathrm{~cm}$ & 5 & 5 & 7 & necrosis spread $<5 \mathrm{~cm}$ \\
necrosis spread $>5 \mathrm{~cm}$ & 6 & 6 & 8 & necrosis spread $>5 \mathrm{~cm}$ \\
\hline
\end{tabular}

score was 1.86 , and the lowest score (mean of 0.47 ) was recorded in 2013 (Table 2). Each year, about one-third of the progeny did not show any symptoms, except for 2016 when the proportion was $61.0 \%$, with $29(11.2 \%)$ out of 258 genotypes not expressing any symptoms in any year. The highest mean score for an individual genotype was 6.0 in 2012, 3.2 in 2013, 3.0 in 2015, 4.0 in 2016 and 6.0 in 2017. For 147 (57.0\%) progeny, the mean score was 1 or lower and the highest average score was 5.95 (Fig. 2a). Additional file 1: Figure S1 shows the proportion of the seven rankings for each progeny.

Since not all progeny were consistently inoculated in every year due to alternate flowering and/or loss of trees, an additional evaluation of the year effect was performed on the genotypes that were inoculated in every year of each of the periods 2011-2013 and 2015-2017, and combined for the 2011-2017 period. Significant year effects were observed (Additional file 2: Figure S2a-c), as well as significant genotype effects (Additional file 3:Figure S3a-c) in this analysis. Flower clusters of 131 genotypes of this German population were phenotyped at least once in each of the 2011-2013 (genotypes grafted on 'M9') and 2015-2017 (genotypes grafted on 'B9') periods, which showed a correlation of $r=0.76$ for the mean scores of the genotypes between the two time periods.

The mean disease scores from the single-year phenotyping of the New Zealand 'Royal Gala' x Mr5 family of 143 plants ranged from 0 to 5.95 . This population displayed a somewhat higher mean rate of infection (2.3) than the German family, with only one progeny of the NZ family not showing any symptoms (Fig. 2b), and only $23(16 \%)$ exhibited a mean infection score of 1 or lower.

\section{Shoot inoculation and assessment}

The ranking of the mean PLL for each of the 230 progeny of the 'Idared' $\times$ Mr5 population in 2012 displayed a strong bias towards resistance (Fig. 3a). While inoculated scions of 15 progeny showed 100\% PLL, inoculated shoots of $70 \%$ of the progeny, together with Mr5, did not exhibit any necrosis, which resulted in a mean PLL for the progeny of $16.2 \%$. The correlation between the mean scores of flowers and PLL of shoots in the orchard was $r=0.61$.
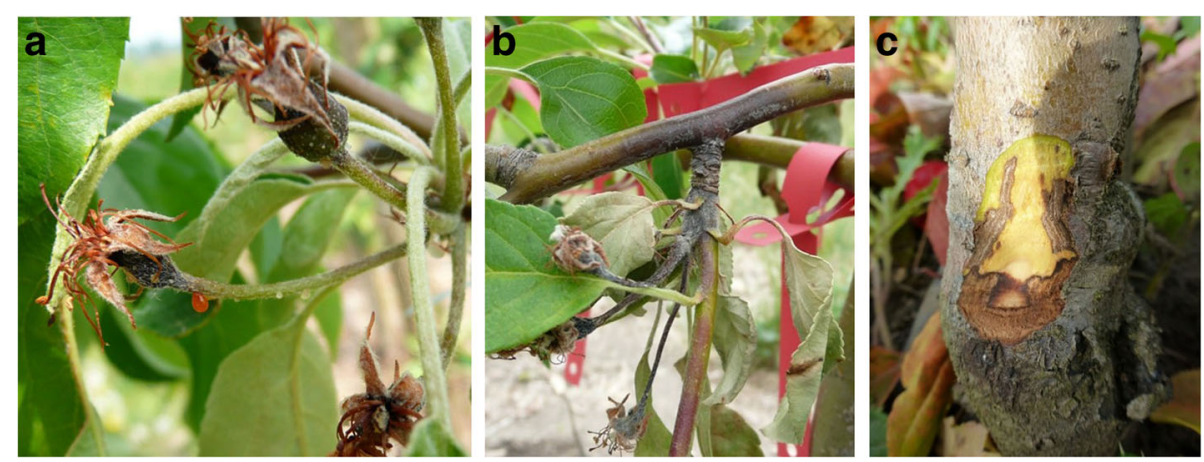

Fig. 1 Fire blight symptoms of apple flowers, shoot and rootstock. a Symptomatic flower stem/fruit stem (scoring value 2) with ooze b) Shoot necrotic lesion $<5 \mathrm{~cm}$ (scoring value 5) c) Rootstock blight, showing the sharp separation between healthy and symptomatic tissue 
Table 2 Total number of trees and number of flowering trees and flower clusters, the annual mean fire blight infection score of the progeny and parents of an 'Idared' $\times$ Malus xrobusta 5 (Mr5) population inoculated with Erwinia amylovora strain Ea222_JKI in the period 2011-2017 in Germany. For the progeny, the percentage of progeny rated Class 0 (i.e. no infection) is presented for each

\begin{tabular}{|c|c|c|c|c|c|c|c|c|c|c|c|c|}
\hline \multirow[t]{4}{*}{ Year $^{a}$} & \multicolumn{6}{|c|}{ Progeny } & \multicolumn{6}{|c|}{ Parents } \\
\hline & \multirow{3}{*}{$\#$} & \multirow{2}{*}{\multicolumn{2}{|c|}{ \# trees flowering }} & \multirow{3}{*}{$\begin{array}{l}\text { \# flower } \\
\text { clusters } \\
\text { inoculated }\end{array}$} & \multirow{3}{*}{$\begin{array}{l}\text { Mean } \\
\text { score }^{b}\end{array}$} & \multirow{3}{*}{$\%$ Class 0} & \multicolumn{3}{|c|}{ 'Idared' } & \multicolumn{3}{|l|}{$\mathrm{Mr5}^{\mathrm{c}}$} \\
\hline & & & & & & & \multirow{2}{*}{$\begin{array}{l}\# \\
\text { trees }\end{array}$} & \multirow{2}{*}{$\begin{array}{l}\text { \# flower } \\
\text { clusters } \\
\text { inoculated }\end{array}$} & \multirow{2}{*}{$\begin{array}{l}\text { Mean } \\
\text { score }^{b}\end{array}$} & \multirow{2}{*}{$\begin{array}{l}\# \\
\text { trees }\end{array}$} & \multirow{2}{*}{$\begin{array}{l}\text { \# flower } \\
\text { clusters } \\
\text { inoculated }\end{array}$} & \multirow{2}{*}{$\begin{array}{l}\text { Mean } \\
\text { score }^{b}\end{array}$} \\
\hline & & Total & Mapping population & & & & & & & & & \\
\hline 2011 & 239 & 188 & 91 & 1573 & $1.86 a$ & 34.0 & 0 & & & 1 & 3 & 0 \\
\hline 2012 & 233 & 228 & 111 & 3367 & $0.95 c$ & 35.1 & 0 & & & 1 & 20 & 0 \\
\hline 2013 & 173 & 154 & 65 & 2722 & $0.47 e$ & 37.0 & 0 & & & 1 & 35 & 0 \\
\hline 2015 & 150 & 148 & 126 & 2546 & $0.75 d$ & 29.1 & 10 & 112 & $2.01 \mathrm{C}$ & 5 & 58 & $0.28 a$ \\
\hline 2016 & 150 & 59 & 46 & 325 & $1.11 \mathrm{bc}$ & 61.0 & 9 & 69 & $3.71 a$ & 8 & 69 & $0.10 a b$ \\
\hline 2017 & 150 & 146 & 125 & 1982 & $1.37 \mathrm{~b}$ & 26.0 & 10 & 100 & $2.81 \mathrm{~b}$ & 9 & 112 & $0.08 \mathrm{~b}$ \\
\hline
\end{tabular}

a Progenies from trial 2011-2013 were grafted on 'M9' and progenies from trial 2015-2017 were grafted on 'B9'

${ }^{b}$ Different letters indicate significantly different means at $a=0.05$

'Data from 2011 to 2013 were not included in analysis

The ranking of the 109 'Royal Gala' $\times$ Mr5 progeny in the glasshouse in New Zealand had a very similar bias to that in the German family (Fig. 3b), with the majority of the genotypes (61\%) exhibiting no symptoms and a mean PLL of 9.1\%. A weak year effect was observed, although the 'None'/'Some' test showed that infection was consistent over both years, but no significant correlation between flower and shoot resistance was found (Horner et al. 2014).

\section{Analysis of rootstock blight}

Of the 83 samples from trees exhibiting symptoms typical of rootstock blight (Fig. 1c) in autumn 2012 and screened by PCR for the presence of E. amylovora, 24 tested positive for rootstock infection with fire blight. The average score of these 24 progenies after inoculation of flowers in 2012 was 1.16, with a maximum of 4.12. The average PLL after shoot inoculation of the same genotypes was 23.8 , with a maximum of 100 . The correlation of scores and PLLs was $r=0.70$. Four out of the 24 genotypes that tested positive for rootstock infection had previously exhibited no symptoms either in the scion or in any floral cluster following inoculation with Ea222 JKI.

\section{Genetic mapping of flower resistance to fire blight}

A subset of the 'Idared' $\times$ Mr5 family (Table 2 ) was genotyped for the genetic mapping of the flower resistance in the six-year experiment in Germany. The scoring data for the individual years, as well as the average scores over both the 2011-2013 and 2015-2017 periods, and all years were used for Kruskal-Wallis analysis, permutation tests, and interval and MQM mapping. To test the robustness of the homogenized ranking scale, interval mapping was performed with both the original (scale 0
8) and the harmonized ranking (scale 0-6) for each year separately, the 2011-2013 and 2015-2017 periods, and both periods together. All the separate analyses displayed the same single major QTL identified on LG3 for both 3 -year periods as well as for all 6 years, with the LOD score ranging from 14 to 23 (Fig. 4). No other significant QTLs for flower resistance to fire blight were detected.

In the New Zealand 'Royal Gala' $\times$ Mr5 population subjected to floral inoculation with Ea236 in the field, IM revealed a QTL controlling resistance to fire blight in the same position as that identified in the 'Idared' $x$ Mr5 population inoculated with Ea222_JKI in Germany, albeit in a somewhat larger interval (Fig. 5). The peak of the LOD curve positioned over markers Fb_R5 and $\mathrm{CH} 03 \mathrm{e} 03$ was $>24$. No other significant QTLs for control of fire blight resistance were observed in this population, using either IM or Kruskal-Wallis analysis.

\section{Genetic mapping of shoot resistance to fire blight}

Kruskal-Wallis analysis of PLL data following shoot inoculation of the 'Idared' $\times$ Mr5 population demonstrated marker-trait association for LG3, with the highest $\mathrm{K}$ value obtained for marker $\mathrm{CH} 03 \mathrm{e} 03$. Genotypes with the $185 \mathrm{bp}$ allele of $\mathrm{CH} 03 \mathrm{e} 03$ in coupling phase with resistance exhibited a mean PLL of $0.2 \%$ compared with a mean PLL of $37.5 \%$ exhibited by genotypes expressing the $207 \mathrm{bp}$ allele in repulsion phase to resistance. Interval mapping resulted in a LOD of 9.8 for $\mathrm{CH} 03 \mathrm{e} 03$, well exceeding the threshold of 2.8 (data not shown).

As genotype data were not available for all the shootinoculated plants of the 'Royal Gala' $\times$ Mr5 population in the glasshouse, IM was performed on a subset of 60 plants. This analysis revealed a broad, low-significance QTL on LG3 of Mr5, which aligned with the QTL 


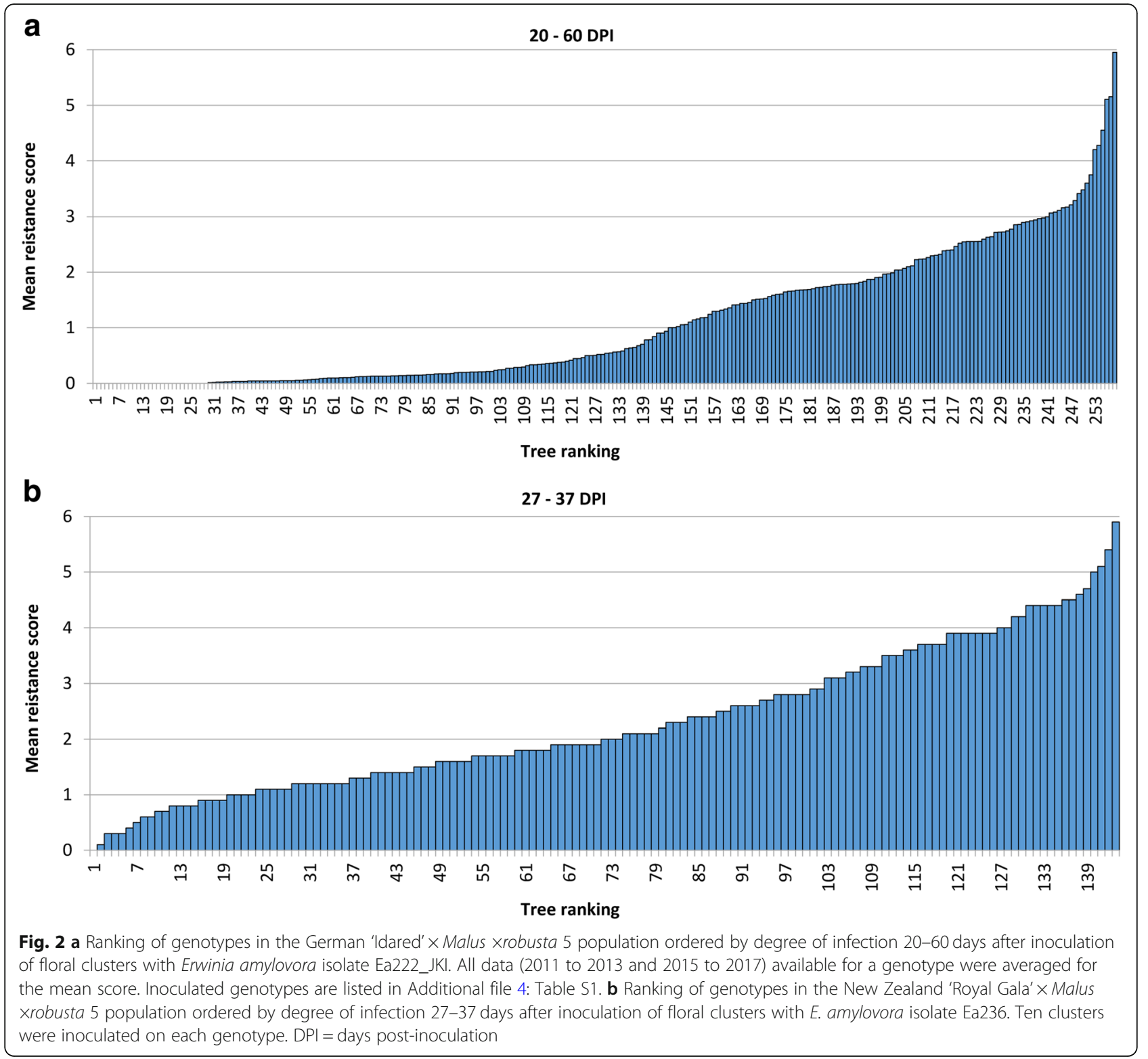

identified by Kruskal-Wallis analysis in the 'Idared' $x$ Mr5 population (Fig. 5). No other associations of phenotype with genotype were identified in the 'Royal Gala' $\times$ Mr5 population.

\section{Discussion}

Fire blight resistance has long been thought to be quantitative, and a number of QTLs from a range of sources have been reported to date [46]. However, mapping of fire blight resistance in Malus has been performed exclusively with data generated from artificial shoot inoculations [12, 14, 16-18]. A reasonable justification for using shoot blight severity as a measurement for resistance according to Harshman et al. [47], is that shoot infection generally leads to structural damage and ultimately economic losses over time. However, the common practice of utilizing only shoot inoculation to map fire blight resistance has resulted in a limited understanding of the genetic control of floral fire blight resistance: breeders have been uncertain whether genetic markers for $\mathrm{Mr} 5$ resistance to fire blight derived from QTL mapping of shoot inoculation data [45] are also valid for marker-assisted selection (MAS) for resistance following floral infection, which is the usual point of entry in the field. Also, optimized infection conditions for the pathogen in the glasshouse may overestimate susceptibility, whereas artificial inoculation in the orchard does not guarantee infection or progress of the disease if weather conditions critical for fire blight development are suboptimal. In the latter case, we tried to improve flower infection conditions by covering the flowers to protect them from unfavorable weather conditions both in Germany and New Zealand. 


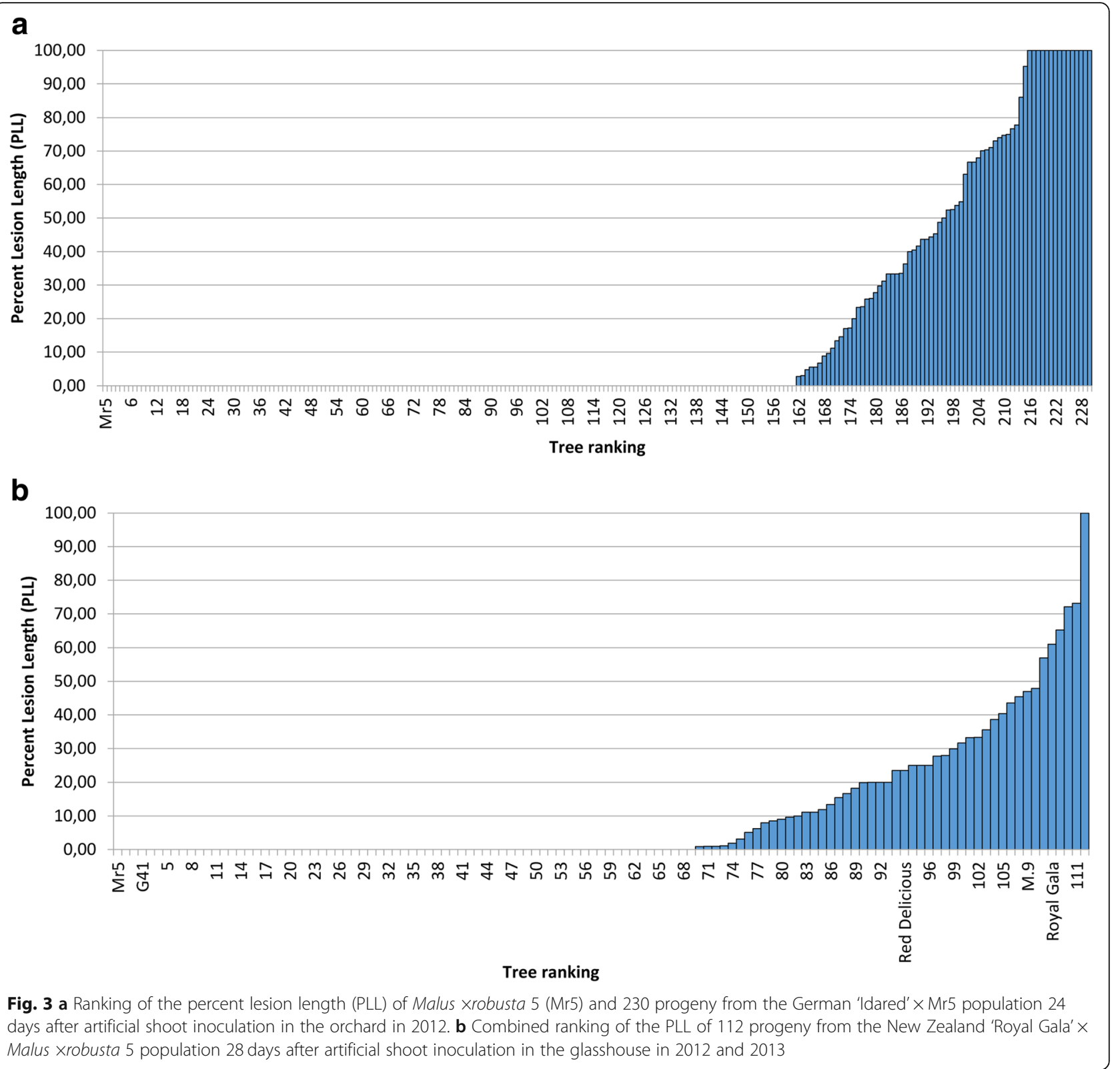

Reliable phenotypic evaluation protocols critical for the genetic mapping of fire blight resistance were adopted for our study and the disease scoring was harmonized to ensure comparability across the two different populations in the two countries. While there were many confounding factors associated with the geographic distance between the two studies (differences in $E$. amylovora isolates; time of year; inoculation techniques; number of years), the phenotyping results were very similar in general, and resulted in identification of the same LG3 QTL on the Mr5 genome.

In the German experiment, a correlation of $r=0.61$ was obtained between the results of floral and shoot inoculations, which was higher than the weak correlation $(0.25<\mathrm{r}<0.44)$ found by Thibault and Le Lezec [35] for 'Gala'. This may be explained by the large genetic effect of the Mr5 QTL, whereas the results for 'Gala', a susceptible cultivar, might have been influenced mainly by environmental conditions. The correlation between flower resistance of progeny grafted onto both 'M9' and 'B9' rootstocks was high $(r=0.76)$, in spite of the climatic conditions during inoculation being different during the different periods of observations. The significant year effects on the mean scores over 6 years of floral infection on the 'Idared' $\times$ Mr5 progeny and the susceptible parent 'Idared' provide further evidence that environmental conditions influence fire blight infection. Van der Zwet et al. [48] argued that weather is one of the most 


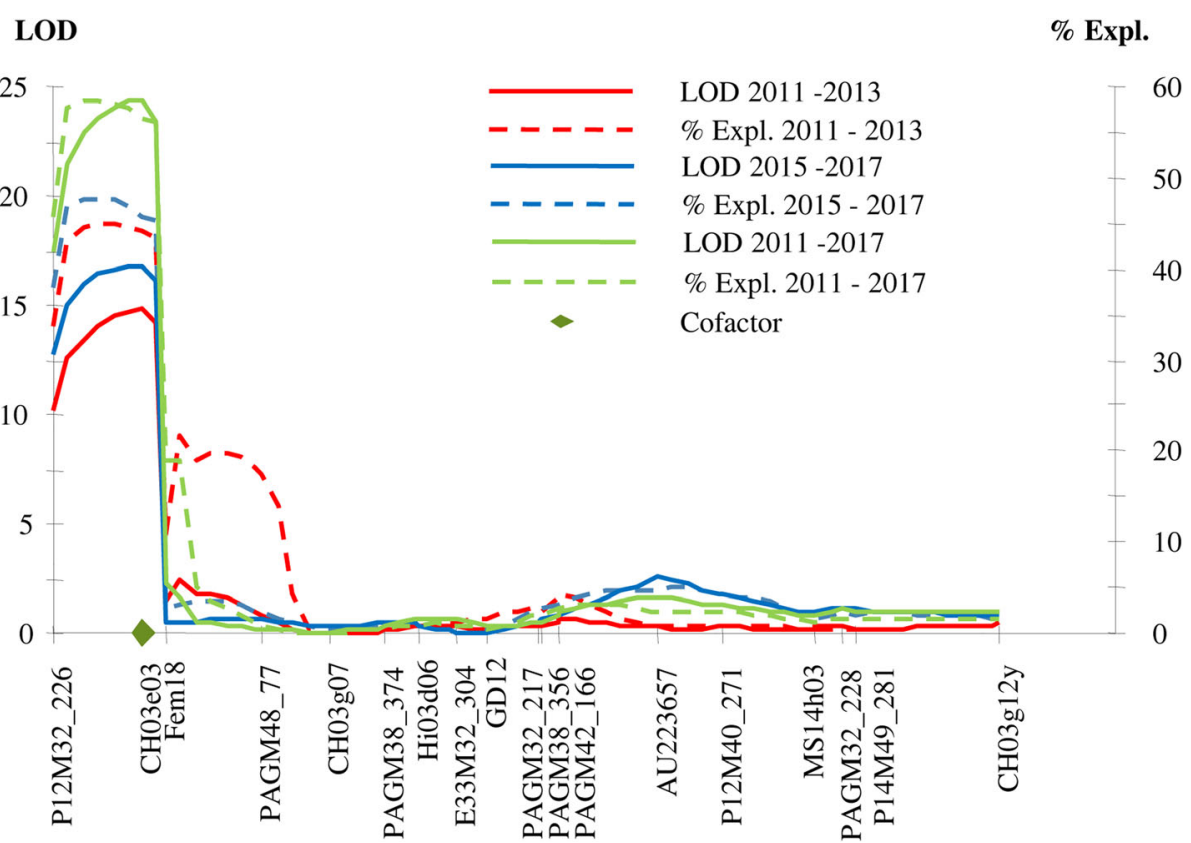

Fig. 4 Logarithm of odds (LOD) score and the percentage of the phenotypic variation explained (\% Expl.) by the genetic markers after MQM mapping of disease infection data following artificial flower inoculation with Ea222_JKI along linkage group 3 of Malus $\times$ robusta 5 (Mr5) in the German 'Idared' $\times$ Mr5 population based on the average median of the genotypes for the periods 2011-2013, 2015-2017 and $2011-2017$. Cofactor = marker with the highest LOD score after interval mapping was set as co-factor

important factors contributing to fire blight incidence in its host. Although these environmental effects were not investigated in detail, it is plausible that conditions were more favorable for E. amylovora in 2011, when the highest infection rate was observed, and less favorable in 2013, the year with the lowest infection rate. However, as loss of susceptible trees also occurred, the data set of second and third year inoculations has an additional bias towards more resistant trees. Typical differences in reactions among genotypes to this pathogen have also been previously reported for shoot blight evaluations in the glasshouse [18].

E. amylovora is capable of migrating through healthy scion tissue into the rootstock, causing rootstock blight [49], which can lead to the death of a tree grafted on susceptible rootstocks [50]. Although 'B9' is susceptible to fire blight, it appears to be resistant as a rootstock, leading LoGiudice et al. [51] to suggest that it suppresses the multiplication of E. amylovora. In our study, a good proportion of the trees of the 'Idared' $\times$ Mr5 population grafted on 'M9' displayed conspicuous rootstock blight symptoms, which was confirmed by PCR on rootstock samples, even though in some cases the scion genotype had not exhibited disease symptoms. However, the same genotypes grafted onto 'B9' exhibited no rootstock blight. To prevent tree death due to fire blight infection, a combination of both resistant rootstock and scion appears to be necessary and this should be further investigated.
QTL mapping using phenotype data sets for each of the 6 years of artificial flower inoculation with E. amylovora in the 'Idared' $\times$ Mr5 population, and for the single year in the 'Royal Gala' $\times$ Mr5 population, resulted in the detection of a single major QTL for control of floral fire blight resistance on LG3 of Mr5, although the QTL was slightly broader in the 'Royal Gala' $\times$ Mr5 population. This flower resistance QTL appears to be the same as the shoot blight resistance QTL from Mr5 reported previously $[14,15,45]$ and was re-confirmed here through the phenotyping of subsets of these populations for this trait, both in the field in Germany and in the glasshouse in New Zealand. Taken together, results of the current study provide strong evidence that fire blight resistance in Mr5 is controlled by the same major QTL on LG3, independent of the infected host tissue and a range of environmental conditions during infection.

Since the QTL explains a large proportion of the phenotypic variation $[14,15]$, it can be regarded as a majoreffect gene: such genes generally tend to be less influenced by the environment. While our study confirmed that the LG3 QTL for shoot resistance applies to flower resistance, the low correlation between the shoot and flower screening methodologies identified in a preliminary analysis of the NZ 'Royal Gala' $\times$ Mr5 population [52] suggests that other undetected resistance factors may be present.

The robustness of the LG3 QTL under different phenotyping conditions makes it a solid choice for development 


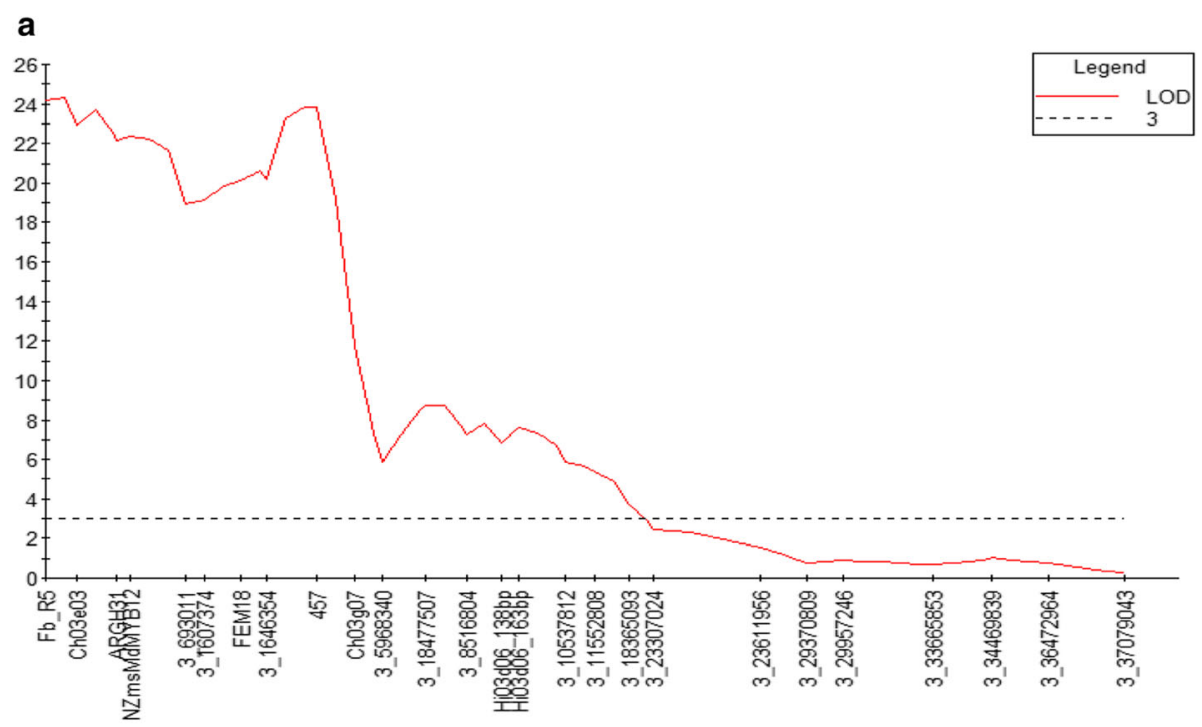

b

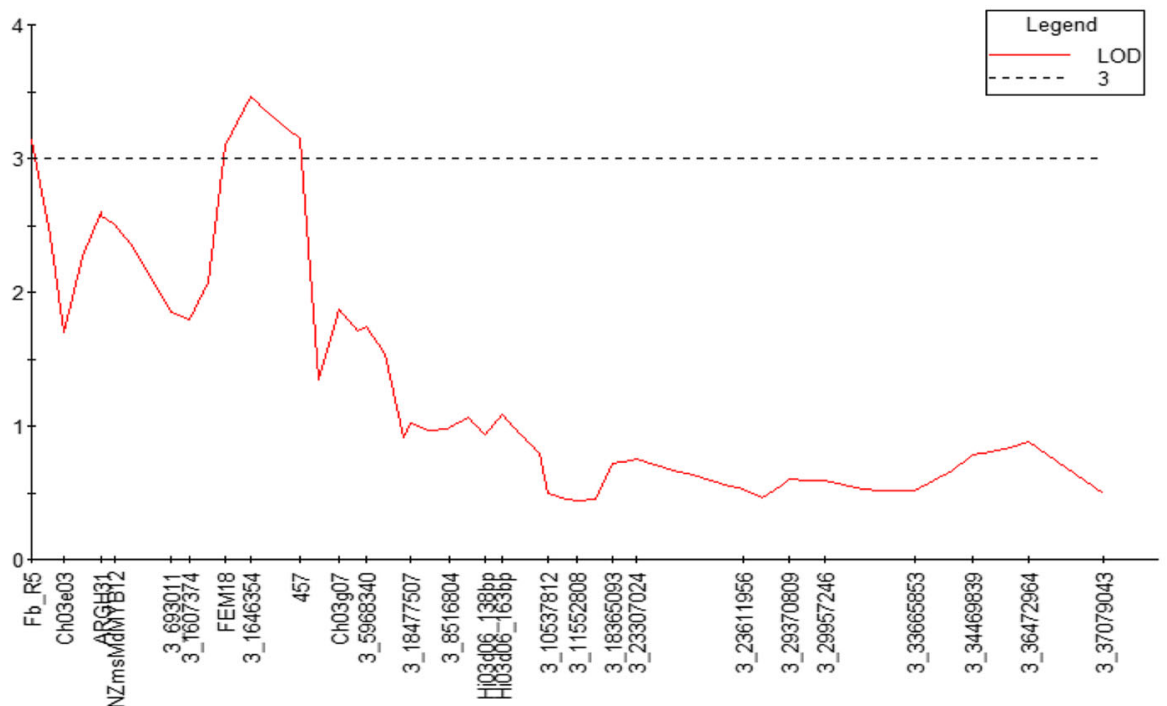

Fig. 5 Interval mapping of quantitative trait loci (QTLS) on linkage group 3 of Malus xrobusta 5 for control of fire blight resistance following inoculation of flowers in the field (a) and shoots in the glasshouse (b) of the New Zealand 'Royal Gala' $\times$ Malus xrobusta 5 population with Erwinia amylovora isolate Ea236. LOD = logarithm of odds

of high-throughput markers for MAS for fire blight resistance derived from Mr5. We developed the Taqman ${ }^{\text {Tax }} \mathrm{Fb}_{-}$ R5 marker [53] to provide a cost-effective alternative to the MxdRLP1 high-resolution melting (HRM) marker developed earlier, following mapping of fire blight resistance after shoot inoculation in a 'M9' $\times$ Mr5 population [45]. The Fb_R5 marker has been employed for MAS in populations from the PFR rootstock breeding programme during the past year.

\section{Conclusions}

We have clearly demonstrated that the strong QTL controlling fire blight resistance in the flowers of Mr5 is located in the same position on LG3 as the one identified through shoot infection. Data gained from the method of inoculating flowers with $E$. amylovora led precisely to the detection of the locus on LG3 in each year of inoculation under two different environments. Although with this method, infection of tissue through micro wounds close to inoculated flowers cannot be excluded, it is highly unlikely that the results obtained are biased in favour of shoot inoculation through these micro wounds rather than by flower inoculation, especially, as it is impossible to have wounds on the same genotypes each year and in both countries, which could have led to the detection of the exact same locus.

The position of the QTL has been demonstrated to be independent of environment through the use of two 
progenies derived from crosses of $\mathrm{Mr} 5$ with different fire blight-susceptible apple parents grown and phenotyped in Germany and New Zealand. In Germany, the QTL was stable over 6 years of floral inoculation in the field as well as independent of rootstock. Nevertheless, this study is limited by the fact that flower inoculation of the NZL population was done only once and infection in the orchard depended on favorable conditions for the pathogen, but even under best conditions, infection can still not be guaranteed. Also, the distribution of the pathogen in asymptotic tissue cannot be excluded. Asymptomatic tissue could be the source for rootstock blight through internal migration of the pathogen leading to the death of the tree or the source for pathogen delivery to other trees. Future studies should determine the correlation between resistant genotypes and asymptomatic tissue if feasible.

To our knowledge, this is the first report of the identification of a QTL controlling fire blight resistance in flowers. Validation of the exact genetic control of this floral resistance is still required to ensure the effective application of MAS. As the strongest fire blight QTLs tend to be found in wild Malus species, we anticipate that shoot phenotyping will remain a suitable proxy for flower resistance phenotyping in introgressing these other QTLs into domesticated apple and for QTL mapping as a precursor to MAS for durable resistance.

\section{Methods}

\section{Plant material}

Two independent segregating populations were derived from crosses between a susceptible apple cultivar and the fire blight resistance donor Mr5. The German population consisted of 258 progeny derived from an 'Idared' $\times$ Mr5 cross, which were grafted onto 'M9' rootstock and planted in the Kirschgartshausen research orchard of the Julius Kühn-Institut (JKI) in 2010. Additional trees of a subset of 150 genotypes of the population grafted onto Budagovski9 ('B9') rootstock were planted there in 2014. Grafted plants of the respective parents were included as controls in both years, of which the susceptible control 'Idared' planted in 2010 did not establish. A subset of 140 progeny of the same population had been used previously to establish the genetic map [28], which was used for QTL mapping. The New Zealand population consisted of 287 progeny from a 'Royal Gala' $\times$ Mr5 cross grafted on 'M27' rootstock and planted in the Hawke's Bay research orchard of The New Zealand Institute for Plant and Food Research Limited (PFR). Evaluation for floral fire blight resistance was performed on 143 progeny of the population. A subset of 112 of these (78\%) were grafted onto 'M9' rootstock, with up to 10 replicates/genotype, and raised in the glasshouse for shoot inoculation.
Cultivars and the wild Malus accession Mr5 are maintained in the NZ and JKI germplasm collections since decades; seeds of populations were obtained from crosses in the respective institute and rootstocks for grafting were obtained from nurseries.

\section{Inoculum}

In Germany, strain Ea222_JKI (Internal collection of $E$. amylovora strains held at JKI, Quedlinburg) from frozen stock was used for E. amylovora inoculation. The frozen stock was prepared by pelleting cells, obtained from liquid cultures grown overnight at $28^{\circ} \mathrm{C}$, at $140 \mathrm{rpm}$ in StI medium (Roth, Karlsruhe) and re-suspending the cell pellets in sterile $15 \% \mathrm{v} / \mathrm{v}$ glycerol for storage at $-80^{\circ} \mathrm{C}$ until use. Inoculum was prepared by slowly thawing the cell suspensions and diluting them with sterile water to a final concentration of $1 \times 10^{9}$ colony forming units $(\mathrm{cfu}) / \mathrm{mL}$ using photometric measurement and validated by live cell counts from dilution plating on St1 agar. E. amylovora strain Ea222_JKI [27] was used previously to detect several major resistance QTLs in Malus [14, 17, 18], including the QTL of Mr5 on LG3 after artificial shoot inoculation in the greenhouse.

In New Zealand, strain Ea236 (International Collection of Micro-organisms from Plants (ICMP), Manaaki Whenua, Landcare Research New Zealand Ltd) was grown on King's B agar [54] for $48 \mathrm{~h}$ at $26^{\circ} \mathrm{C}$ from stock held at $-80^{\circ} \mathrm{C}$. Inoculum was prepared freshly by collecting bacteria from the medium and suspending them to a final concentration of $1 \times 10^{9} \mathrm{cfu} / \mathrm{mL}$ in a phosphate buffered saline (PBS) solution at pH 7.2 using photometric measurement and validated by live cell counts from dilution plating on King's B medium.

\section{Flower inoculation and phenotyping}

In Germany, flower inoculation of the 'Idared' $\times \mathrm{Mr} 5$ population in the Kirschgartshausen orchard was undertaken from 2011 to 2013 for the progeny grafted on 'M9' rootstock, and from 2015 to 2017 for the progeny grafted on 'B9' rootstock. Young flowers were inoculated with the Ea222_JKI suspension using an EcoSpray TLCsprayer (Roth, Karlsruhe). Each flower cluster was sprayed with approximately $100 \mu \mathrm{L}$ inoculum and bagged with a plastic bag, which was removed 5 days after inoculation. Disease assessment was performed 2060 days after inoculation.

At the PFR Hawke's Bay site, 10 floral clusters on a single tree of each genotype were inoculated in the orchard with isolate Ea236 in the period 2-30 September 2009 as the flower clusters reached the standard cluster maturity, using a DeVilbiss atomizer No. 15 with a final load of $10^{5.6} \mathrm{cfu} /$ flower. Each floral cluster was bagged with a plastic bag, and then covered in aluminum foil to shade the flowers to prevent overheating in direct 
sunshine. Bags were removed 3 days after inoculation and disease assessment was performed at 9-12 and 2737 days after inoculation.

Infection of the floral clusters was assessed in a seven-class in-house ranking system in New Zealand and in a nine-class in-house system in Germany. To harmonize the datasets, the German 0-8 scale was transformed to the New Zealand scale 0-6 (Table 1). In Germany, each season, the trees were sanitized by extensive pruning following evaluation. Symptomatic tissue was removed and affected shoots were cut back deep into the healthy regions. Figure 1a, b shows fire blight symptoms after inoculation of flowers.

\section{Shoot inoculation and phenotyping}

In Germany in 2012, shoot inoculation was performed on 230 genotypes in the orchard to compare results obtained in glasshouse experiments with field data. Inoculum of E. amylovora Ea222_JKI was prepared as described above and sprayed onto a pair of scissors that were used to cut the tips of the two youngest leaves on each of three young shoots per tree. Disease severity was evaluated 24 days post inoculation and calculated as percent lesion length (PLL) of the shoot, by dividing the symptomatic shoot length by the total length of shoot and multiplying by 100 .

In New Zealand, a subset of 112 of the 143 florally inoculated plants was also assessed for shoot resistance. Progeny were carefully selected to ensure that the population subset to be screened had plant numbers that fell evenly into each of the floral resistance classes of 0-6. Up to 10 replicates of actively growing shoots (minimum length of $16 \mathrm{~cm}$ ) from each of the 112 progeny, and replicated parent and control plants ('Royal Gala', Mr5, 'M26', G41, 'Red Delicious' and 'M7') grown on 'M9' rootstock were inoculated in both 2012 and 2013 by cutting the tips of the two uppermost unfolded leaves with scissors that had been dipped in to a $10^{9} \mathrm{cfu} / \mathrm{mL}$ suspension of E. amylovora. The inoculated plants were incubated in the glasshouse, with the length of necrosis of each shoot and total shoot length being measured 28 days post-inoculation (DPI). A mean length of necrotic shoot was estimated for each plant using Genstat's CENSOR procedure to account for the possibility that infections that had completely infected the shoot, would have grown longer on a longer shoot. Disease severity was calculated as PLL. Progeny were also classified into two groups depending on whether any of the replicates became infected ('Some') or not ('None'). This was done for both the 2012 and 2013 data, creating a $2 \times 2$ classification.

\section{Rootstock blight verification by polymerase chain reaction}

During field assessment in Germany, a number of trees developed symptoms of rootstock blight (Fig. 1c) despite pruning. This was especially prevalent during summer/ autumn 2012. To confirm the presence of E. amylovora, a sample was taken from 83 trees displaying such symptoms, at the transition between healthy and symptomatic tissue from the graft union. Bacteria were washed from the tissue by shaking several small slivers in $1 \mathrm{~mL}$ water for $10 \mathrm{~min}$. A $100-\mu \mathrm{L}$ aliquot of the resulting suspension was used to inoculate $1 \mathrm{~mL}$ StI medium cultures each for analysis by polymerase chain reaction (PCR). Sample preparation and PCR were performed with the primer combination \#149 (CCGAAGAACGATTGCACTAC) and \#150 (CGGTTAGTTAGCGCAGTCTC) as described by Wensing et al. [55]. Sample dilutions from 10 - to 1000-fold were tested for each sample, to remove traces of PCR inhibitory compounds.

\section{DNA extraction and genotyping of 'Royal Gala' $\times$ Mr5 population}

Genomic DNA was extracted from young freeze-dried leaves harvested from 109 trees of the 'Royal Gala' $\times$ Mr5 population and its parents, using the QIAGEN DNeasy ${ }^{\circ}$ Plant Mini Kit (QIAGEN GmbH, Hilden, Germany) according to the manufacturer's protocols. This DNA was amplified and hybridized to the apple and pear Infinium ${ }^{\circ}$ II $9 \mathrm{~K}$ SNP array [56] following the Infinium ${ }^{\bullet}$ HD Assay Ultra protocol (Illumina Inc., San Diego, USA) and scanned using an Illumina HiScan. Data were analyzed using Illumina ${ }^{\circledR}$ GenomeStudio v 1.0 software Genotyping Module, with a GenCall Threshold of 0.15. Additional simple sequence repeat (SSR) markers mapping at the top of LG3 were screened over the population to enable comparison of the results in the present study with those reported by Gardiner et al. [45]. Fb_R5 is a Taq$\operatorname{man}^{\mathrm{Tm}}$ marker developed from the sequence around the $M x d R L P 1$ marker [45] and is used routinely for markerassisted selection for fire blight resistance derived from Mr5 in PFR breeding programmes [57]. The Fb_R5 marker was developed from the FB-MR5-NZsnEH034548_R249 SNP [58] and is available as a custom Taqman ${ }^{\mathrm{TM}}$ assay (assay AH21B92; Thermo Fisher Scientific).

\section{Genetic mapping and statistical analyses}

The Mr5 map established by [28] was used as a template for QTL mapping in the 'Idared' $\times$ Mr5 population and a new genetic map was generated for Mr5 in the 'Royal Gala' $\times$ Mr5 population using SNP array data and supplementary markers from LG3 of the 'M9' $\times$ Mr5 map [45].

MapQTL 5 [59] was used throughout this study for Kruskal-Wallis analyses, interval mapping (IM) and multiple QTL model (MQM) mapping. Thresholds were determined by permutation tests with a significance level of $\alpha=0.05$. The marker with the highest logarithm of odds (LOD) score close to a QTL was included as cofactor for MQM mapping. 
Statistical analyses to determine whether trial year caused significant differences in the average score, at a significance level of $\alpha=0.05$, were performed using SAS GLIMMIX (Generalized Linear Mixed Model) procedure (SAS-Institute 2013, [60]. Therefore, the averages of the mean scores of all clusters for a single year were calculated.

\section{Supplementary information}

Supplementary information accompanies this paper at https://doi.org/10. 1186/s12870-019-2154-7.

Additional file 1: Figure S1. Ranking of genotypes in the German 'Idared' $\times$ Malus $\times$ robusta 5 population ordered by degree of infection 20-60 days after inoculation of floral clusters with Ea222 JKI. All data (2011 to 2013 and 2015 to 2017) available for a genotype were averaged for the mean score. Different colours indicate the percentages of the scores 0-6 for the floral clusters of a genotype.

Additional file 2: Figure S2. Significant differences between mean resistance scores of individual years in the German 'Idared' $\times$ Malus xrobusta 5 population. Only genotypes tested in all years of the respective period were utilized for the analysis. The significance level is $a=0.05$. a. Period 2011 to 2013. b. Period 2015 to 2017. c. Period 2011 to 2017

Additional file 3: Figure S3. Significant differences between mean resistance scores of genotypes in the German 'Idared' $\times$ Malus xrobusta 5 population. Only genotypes tested in all years of the respective period were utilized for the analysis. Genotypes without any symptoms in the respective period were removed from analyses, because of the lack of standard deviation. Different letters on the right side indicate significanet differences at a level of $a=0.05$. a. Period 2011 to 2013. b. Period 2015 to 2017. c. Period 2011 to 2017

Additional file 4: Table S1. Number of inoculated flower clusters per genotype, year and scoring results.

\section{Abbreviations}

bp: base pairs; cfu: colony forming units; F1: 1 filial generation; GLIMMIX: Generalized linear mixed model; IM: Interval mapping; JKI: Julius Kühn-Institut; LG: Linkage group; LOD: Logarithm of the odds; MAS: Marker assisted selection; mL: milli litre; MQM: Multiple QTL model; Mr5: Malus xrobusta 5; NZ: New Zealand; PBS: Phosphate buffered saline; PCR: Polymerase chain reaction; pH: potentia Hydrogenii; PLL: Percentage lesion length; QTL: Quantitative trait locus; rpm: rounds per minute; SNP: Single nucleotide polymorphism; VN: Volume per volume

\section{Acknowledgements}

The New Zealand part of the project was funded by the Strategic Science Investment Fund of the New Zealand Ministry of Business, Innovation and Employment. The Deutsche Forschungsgemeinschaft (DFG), projects numbers AOBJ574457 and AOBJ577770, supported the German part of the project.

\section{Authors' contributions}

AP, AW designed the German project part and did statistical analyses. VB designed the New Zealand project part. SG designed and led the molecular aspects of the New Zealand project part. DC, CO-T performed the genetic map construction. AP, DC, CO-T, TW did the QTL mapping analyses. AW, CH, KR and $\mathrm{MH}$ performed the phenotyping. AW, CO-T, CH and SM performed laboratory analyses. ES and MT performed the Illumina genotyping. AP, AW, HF, MH, M-VH, $\mathrm{O}-\mathrm{FE}, \mathrm{SG}$ and VB contributed to writing the manuscript. All authors read and approved the final document.

\section{Funding}

The New Zealand part of the project was funded by the Strategic Science Investment Fund of the New Zealand Ministry of Business, Innovation and Employment. The Deutsche Forschungsgemeinschaft (DFG), projects numbers AOBJ574457 and AOBJ577770, supported the German part of the project. The funding organizations had no role in in the design of the study and collection, analysis, and interpretation of data and in writing the manuscript.

Availability of data and materials

The data that support the findings of this study are available from the authors upon reasonable request.

Ethics approval and consent to participate

Not applicable.

\section{Consent for publication}

Not applicable.

\section{Competing interests}

The authors declare that they have no competing interests.

\section{Author details}

'Julius Kühn-Institut (JKI), Federal Research Centre for Cultivated Plants, Institute for Breeding Research on Fruit Crops, Pillnitzer Platz 3a, 01326 Dresden, Germany. ${ }^{2} J u l i u s$ Kühn-Institut (JKI), Federal Research Centre for Cultivated Plants, Institute for Plant Protection in Fruit Crops and Viticulture, Schwabenheimer str. 101, 69221 Dossenheim, Germany. ${ }^{3}$ The New Zealand Institute for Plant and Food Research Limited (PFR), Hawke's Bay Research Centre, Private Bag 1401, Havelock North 4157, New Zealand. ${ }^{4}$ Julius Kühn-Institut (JKI), Federal Research Centre for Cultivated Plants, Institute for Resistance Research and Stress Tolerance, Erwin-Baur-Str. 27, 06484 Quedlinburg, Germany. ${ }^{5}$ PFR, Palmerston North Research Centre, Private Bag 1600, Palmerston North 4442, New Zealand. ${ }^{6}$ Research and Innovation Centre, Edmund Mach Foundation, 38010 San Michele all'Adige, Italy.

Received: 7 May 2019 Accepted: 21 November 2019

Published online: 02 December 2019

\section{References}

1. Hanke M-V, Flachowsky H. Obstzüchtung und wissenschaftliche Grundlagen Kapitel 13. Apfel (Malus domestica). Berlin: Springer-Verlag; 2017.

2. Winslow CE, Broadhurst J, Buchanan RE, Krumwiede C, Rogers LA, Smith GH. The families and genera of the bacteria: final report of the committee of the society of American bacteriologists on characterization and classification of bacterial types. J Bacteriol. 1920;5(3):191-229.

3. Peil A, Bus VGM, Geider K, Richter K, Flachowsky H, Hanke MV. Improvement of fire blight resistance in apple and pear. Int J Plant Breed. 2009;3:1-27.

4. Russo NL, Robinson TL, Fazio G, Aldwinckle HS. Fire blight resistance of Budagovsky 9 apple rootstock. Plant Dis. 2008;92(3):385-91.

5. Van der Zwet T, Orolaza-Halbrendt N, Zeller W. Fire blight: history, biology, and management. Chapter 3. Losses due to fire blight and economic importance of the disease. Pp 37-41. St. Paul: APS Press/American Phytopathological Society; 2012.

6. Walsh F, Smith DP, Owens SM, Duffy B, Frey JE. Restricted streptomycin use in apple orchards did not adversely alter the soil bacteria communities. Front Microbiol. 2014:4:383

7. Gianessi L, Silvers C, Sankula S, Carpenter J: Plant biotechnology: current and potential impact for improving pest management. US Agriculture: An Analysis of 40 Case Studies 2002, June Report:32.

8. Ngugi HK, Lehman BL, Madden LV. Multiple treatment meta-analysis of products evaluated for control of fire blight in the eastern United States. Phytopathology. 2011;101(5):512-22.

9. O'Rourke D, Janick J, Sansavini S. World apple cultivar dynamics. Chron Hortic. 2003;43:10-3.

10. Aldwinckle HS, Gustafson HL, Forsline PL. Evaluation of the core subset of USDA apple germplasm collection for resistance to fire blight. Acta Hortic. 1999;489:269-72.

11. van der Zwet T, Keil HL. Fire blight, a bacterial disease of rosaceous plants USDA: Wahington DC; 1979.

12. Calenge F, Drouet D, Denancé $C$, Van de Weg WE, Brisset MN, Paulin JP, Durel CE. Identification of a major QTL together with several minor additive or epistatic OTLs for resistance to fire blight in apple in two related progenies. Theor Appl Genet. 2005;111(1):128-35. 
13. Khan M, Duffy B, Gessler C, Patocchi A. QTL mapping of fire blight resistance in apple. Mol Breeding. 2006;17(4):299-306.

14. Peil A, Garcia-Libreros T, Richter K, Trognitz FC, Trognitz B, Hanke MV, Flachowsky H. Strong evidence for a fire blight resistance gene of Malus xrobusta located on linkage group 3. Plant Breed. 2007;126(5):470-5.

15. Peil A, Hanke M-V, Flachowsky H, Richter K, Garcia-Libreros T, Celton J-M, Gardiner S, Horner M, Bus V. Confirmation of the fire blight QTL of Malus xrobusta 5 on linkage group 3. Acta Hortic. 2008;793:297-303.

16. Durel CE, Denancé C, Brisset MN. Two distinct major QTL for resistance to fire blight co-localize on linkage group 12 in apple genotypes 'Evereste' and Malus floribunda clone 821. Genome. 2009;52(2):139-47.

17. Emeriewen OF, Peil A, Richter K, Zini E, Hanke M-V, Malnoy M. Fire blight resistance of Malus Xarnoldiana is controlled by a quantitative trait locus located at the distal end of linkage group 12. Eur J Plant Pathol. 2017;1011:1011-8.

18. Emeriewen OF, Richter K, Kilian A, Zini E, Hanke MV, Malnoy M, Peil A Identification of a major quantitative trait locus for resistance to fire blight in the wild apple species Malus fusca. Mol Breeding. 2014;34(2):407-19.

19. Fahrentrapp J, Broggini GAL, Kellerhals M, Peil A, Richter K, Zini E, Gessler C. A candidate gene for fire blight resistance in Malus $\times$ robusta 5 is coding for a CC-NBS-LRR. Tree Genet Genomes. 2013;9(1):237-51.

20. Broggini GA, Wöhner T, Fahrentrapp J, Kost TD, Flachowsky H, Peil A, Hanke MV, Richter K, Patocchi A, Gessler C. Engineering fire blight resistance into the apple cultivar 'Gala' using the FB_MR5 CC-NBS-LRR resistance gene of Malus xrobusta 5. Plant Biotechnol J. 2014;12(6):728-33.

21. Emeriewen OF, Richter K, Piazza S, Micheletti D, Broggini GAL, Berner T, Keilwagen J, Hanke M-V, Malnoy M, Peil A. Towards map-based cloning of FB_Mfu10: identification of a receptor-like kinase candidate gene underlying the Malus fusca fire blight resistance locus on linkage group 10. Mol Breeding. 2018;38(8):106.

22. Norelli JL, Aldwinckle HS, Beer SV. Differential host x pathogen interaction among cultivars of apple and strains of Enwinia amylovora. Phytopathology. 1984;74:136-9.

23. Fazio G, Aldwinckle HS, McQuin RP, Robinson T. Differential susceptbility to fire blight in commercial and experimental apple rootstock cultivars. Acta Hortic. 2006;704:527-30.

24. Emeriewen OF, Wöhner T, Flachowsky H, Peil A. Malus Hosts-Erwinia amylovora Interactions: Strain Pathogenicity and Resistance Mechanisms. Front Plant Sci. 2019;10:551.

25. Norelli JL, Aldwinckle HS. Differential susceptibility of Malus spp. cultivars Robusta 5, Novole, and Ottawa 523 to Enwinia amylovora. Plant Dis. 1986;70(1017):1019.

26. Peil A, Flachowsky H, Hanke M-V, Richter K, Rode J. Inoculation of Malus xrobusta 5 progeny with a strain breaking resistance to fire blight reveals a minor QTL on LG5. Acta Hortic. 2011:896:357-62.

27. Vogt I, Wöhner T, Richter K, Flachowsky H, Sundin GW, Wensing A, Savory EA, Geider K, Day B, Hanke MV, et al. Gene-for-gene relationship in the host-pathogen system Malus xrobusta 5-Enwinia amylovora. New Phytol. 2013;197(4):1262-75.

28. Wöhner TW, Flachowsky H, Richter K, Garcia-Libreros T, Trognitz F, Hanke MV, Peil A. QTL mapping of fire blight resistance in Malus xrobusta 5 after inoculation with different strains of Erwinia amylovora. Mol Breeding. 2014;34(1):217-30.

29. Wöhner T, Richter K, Sundin GW, Zhao Y, Stockwell VO, Sellmann J, Flachowsky H, Hanke MV, Peil A. Inoculation of Malus genotypes with a set of Erwinia amylovora strains indicates a gene-for-gene relationship between the effector gene eop1 and both Malus floribunda 821 and Malus 'Evereste'. Plant Pathol. 2018;67:938-47.

30. Thomson SV. Epidemiology of fire blight. In: Vanneste JL, editor. Fire blight The disease and its causative agent, Erwinia amylovora. Edited by. New York: CABI Puplishing; 2000. p. 9-36.

31. Cellini A, Giacomuzzi V, Donati I, Farneti B, Rodriguez-Estrada MT, Savioli S, Angeli S, Spinelli F. Pathogen-induced changes in floral scent may increase honeybee-mediated dispersal of Erwinia amylovora. ISME J. 2019;13(4):847.

32. Lespinasse Y, Paulin JP. Apple breeding programme for fire blight resistance: strategy used and first results. Acta Hortic. 1990;273:285-91.

33. Maas Geesteranus HP, Heyting J. The value of topleaf inoculation to demonstrate genetic resistance in Pomoidae species to Erwinia amylovora (Burr.) Winslow et al. Acta Hortic. 1981;117:75-82.

34. Kleinhempel H, Kegler H, Ficke W, Schaefer H-J. Methods of testing apples for resistance to fire blight. Acta Hortic. 1984;151:261-5.

35. Thibault B, Le Lezec M. Sensibilité au feu bactérien des principales variétés de pommier et de poirier utilisées en Europe. In: Paulin JP, editor. Fire blight of Pomoidae (Erwinia amylovora Burill Winslow et al) Applied Research in Europe (1978-88), EUR 12601. Edited by. Brussels-Luxembourg; 1990. The Commission of the European Communities. p. 96-109.
36. Maroofi A, Mostafavi M. Evaluation of the resistance of apple, pear and quince varieties to fire blight. Acta Hortic. 1996:411:395-9.

37. Le Lezec M, Paulin J-P, Lecomte P. Shoot and blossom susceptibility to fire blight of apple cultivars. Acta Hortic. 1987;217:311-5.

38. Farkas A, Mihalik E, Dorgai L, Bubán T. Floral traits affecting fire blight infection and management. Trees. 2012;26(1):47-66.

39. Pusey P, Curry E. Temperature and pomaceous flower age related to colonization by Erwinia amylovora and antagonists. Phytopathology. 2004; 94(8):901-11.

40. Pusey $P$, Smith T. Relation of apple flower age to infection of hypanthium by Erwinia amylovora. Plant Dis. 2008;92(1):137-42

41. Thomson S, Gouk S. Influence of age of apple flowers on growth of Erwinia amylovora and biological control agents. Plant Dis. 2003:87(5):502-9.

42. Spinelli F, Ciampolini F, Cresti M, Geider K, Costa G. Influence of stigmatic morphology on flower colonization by Erwinia amylovora and Pantoea agglomerans. Eur J Plant Pathol. 2005;113(4):395-405.

43. Spinelli F, Vanneste J, Ciampolini F, Cresti M, Rademacher W, Geider K, Costa G. Potential and limits of acylcyclohexanediones for the control of blossom blight in apple and pear caused by Erwinia amylovora. Plant Pathol. 2007; 56(4):702-10.

44. Pusey P. Effect of nectar on microbial antagonists evaluated for use in control of fire blight of pome fruits. Phytopathology. 1999;89(1):39-46.

45. Gardiner SE, Norelli UL, de Silva N, Fazio G, Peil A, Malnoy M, Horner M, Bowatte D, Carlisle C, Wiedow $\mathrm{C}$, et al. Putative resistance gene markers associated with quantitative trait loci for fire blight resistance in Malus 'Robusta 5' accessions. BMC Genet. 2012;13:25.

46. Khan M, Zhao Y, Korban S. Molecular mechanisms of pathogenesis and resistance to the bacterial pathogen Erwinia amylovora, causal agent of fire blight disease in Rosaceae. Plant Mol Biol Rep. 2012;30(2):247-60.

47. Harshman JM, Evans KM, Allen H, Potts R, Flamenco J, Aldwinckle HS, Wisniewski ME, Norelli JL. Fire blight resistance in wild accessions of Malus sieversii. Plant Dis. 2017;101(10):1738-45

48. Van der Zwet T, Orolaza-Halbrendt N, Zeller W. Fire blight: history, biology, and management. Chapter 11. Effect of host conditions, cultural practices, and environment on disease development. Pp 183-193. St. Paul: APS Press/ American Phytopathological Society; 2012.

49. Norelli JL, Jones AL, Aldwinckle HS. Fire blight management in the twentyfirst century: using new technologies that enhance host resistance in apple. Plant Dis. 2003;87(7):756-65.

50. Aldwinckle H, LoGiudice N, Robinson T, Holleran H, Fazio G, Johnson W, Norelli J. Resistance of apple rootstocks to fire blight infection caused by internal movement of Enwinia amylovora from scion infections. Acta Hortic. 2003;663:229-34.

51. LoGiudice N, Aldwinckle $H$, Robinson T, Fazio $G$. The nature of resistance of the ' B. 9' apple rootstock to fire blight. Acta Hortic. 2004;704:515-20.

52. Horner M, Hough E, Hedderley D, How N, Bus V. Comparison of fire blight resistance screening methodologies. New Z Plant Prot. 2014;67:145-50.

53. Chagné D, Vanderzande S, Kirk C, Profitt N, Weskett R, Gardiner SE, Peace CP, Volz RK, Bassil NV. Validation of SNP markers for fruit quality and disease resistance loci in apple (Malus $\times$ domestica Borkh.) using the OpenArray ${ }^{\circledR}$ platform. Hortic Res. 2019;6(1):30.

54. King EO, Ward MK, Raney DE. Two simple media for the demonstration of pyocyanin and fluorescin. Transl Res. 1954;44(2):301-7.

55. Wensing A, Gernold M, Geider K. Detection of Erwinia species from the apple and pear flora by mass spectroscopy of whole cells and with novel PCR primers. J Appl Microbiol. 2012;112(1):147-58.

56. Chagne D, Crowhurst RN, Troggio M, Davey MW, Gilmore B, Lawley C, Vanderzande S, Hellens RP, Kumar S, Cestaro A, et al. Genome-wide SNP detection, validation, and development of an 8K SNP array for apple. PLoS One. 2012;7:e31745.

57. Gardiner SE. Novel genetic marker technologies revolutionize apple breeding. Acta Hortic. 2017;1174:23-30.

58. Jänsch M, Broggini GL, Weger J, Bus VM, Gardiner S, Bassett H, Patocchi A. Identification of SNPs linked to eight apple disease resistance loci. Mol Breeding. 2015;35(1):1-21.

59. Van Ooijen JW. MapQTL ${ }^{\oplus}$, software for the mapping of quantitative trait loci in experimental populations. Kyazma B.V: Wageningen, The Netherlands; 2004.

60. Schabenberger O. Introducing the GLIMMIX procedure for generalized linear mixed models, SUGI 30 Proceedings; 2005. p. 196-30.

\section{Publisher's Note}

Springer Nature remains neutral with regard to jurisdictional claims in published maps and institutional affiliations. 